OPEN ACCESS

Edited by:

Wenyao $L i$

Shanghai University of Engineering

Sciences, China

Reviewed by:

Xuenian Chen,

Henan Normal University, China

Jun Li,

Tsinghua University, China

*Correspondence:

Qi Yu

kukukoko2004@163.com

Specialty section

This article was submitted to

Energy Materials,

a section of the journal

Frontiers in Materials

Received: 22 June 2019

Accepted: 12 August 2019

Published: 04 September 2019

Citation:

Yu Q, Rong P, Ren S, Jiang $L$ and $L i Y$

(2019) Fabrication and

Electrochemical Performance of

Al-Doped ZnO Nanosheets on Graphene-Based Flexible Substrates.

Front. Mater. 6:208

doi: 10.3389/fmats.2019.00208

\section{Fabrication and Electrochemical Performance of Al-Doped ZnO Nanosheets on Graphene-Based Flexible Substrates}

\author{
Qi Yu ${ }^{1 *}$, Ping Rong ${ }^{1}$, Shuai Ren ${ }^{1}$, Liyun Jiang ${ }^{2}$ and Yapeng $L^{1}$ \\ ${ }^{1}$ School of Materials Science and Engineering, Institute of Graphene at Shaanxi Key Laboratory of Catalysis, Shaanxi \\ University of Technology, Hanzhong, China, ${ }^{2}$ School of Physics and Telecommunication Engineering, Shaanxi University of \\ Technology, Hanzhong, China
}

In this work, Al-doped ZnO (AZO) nanosheets (NSs) were successfully synthesized on graphene-coated polyethylene terephthalate (GPET) flexible substrate via hydrothermal method. Studies have indicated that with the addition of $\mathrm{Al}^{3+}$, the nanostructure of $\mathrm{ZnO}$ gradually grows from nanorods (NRs) to NSs, and the (100), (002), and (101) diffraction peak strength of $\mathrm{ZnO}$ that grows perpendicularly to the substrate along the c-axis weakened. The mechanism of hydrothermal growth of AZO/GPET was also studied. The electrochemical properties of the samples were investigated by cyclic voltammetry (CV) and electrochemical impedance spectroscopy (EIS), and it was concluded that AZO NSs grown on GPET substrates has better capacitance performance than undoped ZnO NRs.

Keywords: $\mathrm{ZnO}$, Al-doped, hydrothermal method, graphene-based flexible substrates, electrochemical performance

\section{INTRODUCTION}

Up to now, energy reserves and environmental contamination are still the focus of extensive attention, especially the problems of air pollution, water pollution, global warming, and renewable energy, which are closely linked with our lives. In order to solve these problems, batteries and supercapacitors have become research hotspots of electrochemical energy storage systems. Among them, supercapacitor (SC), is of great attention in the fields of automobiles (Cao and Emadi, 2011; Biplab et al., 2017), wind power systems (Abbey and Joos, 2007), solar cells (Narayanan et al., 2015; Xu et al., 2015), and so on, because of its great power density, lack of required maintenance, wide operating temperature range, green environmental protection, long cycling life, etc. (Zhao et al., 2011). In addition to those, SCs can provide high power pulses in a short period of time compared to conventional capacitors or storage batteries. SCs, for example, are often used for intelligent start-stop control systems (lightweight hybrid power system), which are particularly prominent in plug-in hybrid electric vehicles (Cao and Emadi, 2011). Due to the different energy storage mechanism, SCs can be divided into electric double-layer capacitors (EDLCs) and faraday pseudo-capacitors. The former generates and stores energy by adsorption of a pure electrostatic charge on the electrode surface and the latter uses redox reaction to store electrical energy in an electrochemical manner (Liu et al., 2014). The properties of SCs are closely related to the electrode materials used, and examples of materials used in current research are: carbon materials 
(Salinas-Torres et al., 2019), metal oxides (Wu et al., 2018) and conductive polymers. Of all electrode materials, carbon materials with high specific surface area and low internal resistance receive more attention, including activated carbon fibers (Ren et al., 2013), carbon aerogel (Liu et al., 2018), carbon nanotubes (Futaba et al., 2006), activated carbon (Wang et al., 2014; Isabel et al., 2016), porous carbon (Yang et al., 2019), and graphene (Zhang et al., 2016; Ren et al., 2018).

The theoretical specific capacity of semiconductor oxides such as $\mathrm{ZnO}, \mathrm{SnO}_{2}$, and $\mathrm{TiO}_{2}$ is 2,3 times that of graphite, which has attracted enormous attention. Among them, $\mathrm{ZnO}$, as a $\mathrm{n}$ type semiconductor, has tremendous senses for the fields of chemicals, electronics, and optics owing to its superior properties [i.e., a large exciton binding energy $(60 \mathrm{meV})$ and a wide bandgap of about $3.3 \mathrm{eV}$ at room temperature] (Klingshirn, 2010). In addition, as the electrode material of supercapacitor, $\mathrm{ZnO}$ has been paid more and more attention because of its advantages of high chemical stability and thermal stability, low cost, environment friendly, and easy doping. However, $\mathrm{ZnO}$ has the disadvantages of poor conductivity and large volume effect in the process of charging and discharging, which affects the practical application of $\mathrm{ZnO}$ as an electrode material. Graphene, a two-dimensional carbon nanomaterial with zero bandgap, is attracted much attention that as a prospective candidate electrode material for EDLCs due to its high carrier mobility, great chemical resistance, large surface area, high conductivity, and transparency (Han et al., 2014; Ren et al., 2018). However, the presence of Van der Waals makes graphene easy to reunite, thus reducing the specific surface area and specific capacity of graphene. Therefore, $\mathrm{ZnO}$ and graphene materials composite and doped, can achieve the complementary advantages of material properties.

Bhirud et al. prepared $\mathrm{N}$-doped $\mathrm{ZnO}$ /graphene (NZO/GR) by situ wet chemical method and studied their electrochemical properties. It was observed, the specific capacitance of NZO/GR was $555 \mathrm{Fg}^{-1}$, which was $529 \mathrm{Fg}^{-1}$ and $20 \%$ higher than pure $\mathrm{ZnO} / \mathrm{GR}$ (Bhirud et al., 2015). $\mathrm{Cu} / \mathrm{ZnO}$ doped graphene nanocomposites was investigated by Jacob et al. (2018). Electrochemical analysis showed that the material has a specific capacity of $630 \mathrm{mAhg}^{-1}$ and retains around $95 \%$ of this capacity after 100 cycles. Faraji and Ani (2014) reviewed the application of microwave-assisted metal oxide thin film electrodes in supercapacitors. And they noted that $\mathrm{ZnO} / \mathrm{GR}$ composites have high specific capacitance and good reversible chargedischarge performance. Many previous studies have used the hummer method to prepare graphene to prepare $\mathrm{ZnO}$ /graphene nanoparticles (Wang et al., 2011; Bu and Huang, 2015; Zhang et al., 2015). Therefore, it is necessary to explore the preparation of $\mathrm{ZnO}$ nanofilms based on transparent conductive flexible graphene-coated polyethylene terephthalate (GPET) substrates.

In this paper, $\mathrm{ZnO}$ nanosheets (NSs) with different $\mathrm{Al}$ doped concentration on GPET substrates were fabricated by a simple-green hydrothermal method, and their electrochemical properties were studied. The effect of adding different concentrations of $\mathrm{Al}$ on electrochemical properties of $\mathrm{ZnO}$ composite nanostructures was compared.

\section{EXPERIMENTAL}

\section{Synthesis of ZnO Nanosheets}

The Al-doped $\mathrm{ZnO}$ (AZO) NSs with different concentrations were prepared on GPET substrates. The $\mathrm{ZnO}$ seed layer (about $30 \mathrm{~nm}$ thickness) was sputtered by radio frequency magnetron sputtering on the surface of GPET substrates, which used acetone (10 min), methanol (10 min), and deionized (DI) water to clean in turn by ultrasonic cleaning machines. In the hydrothermal growth process of AZO NSs, zinc nitrate hexahydrate ( $\mathrm{Zn}$ $\left.\left(\mathrm{NO}_{3}\right)_{2} \cdot 6 \mathrm{H}_{2} \mathrm{O}\right)$, and hexamethylenetetramine $\left(\mathrm{C}_{6} \mathrm{H}_{12} \mathrm{~N}_{4}\right)$ were mixed in DI water to prepare precursor solutions $(30 \mathrm{ml})$. Then added aluminum oxide $\left(\mathrm{Al}_{2} \mathrm{O}_{3}\right)$ as dopant to the solutions with the concentration of 0.1 and $0.05 \mathrm{~mol} / \mathrm{L}$, and kept stirring for $30 \mathrm{~min}$ under mild magnets. The precursor solutions were transferred to a Teflon-lined stainless-steel autoclave, and then the GPET substrates were immersed in it. After that, the autoclave was sealed and put into an oven, and heated at a temperature of $95^{\circ} \mathrm{C}$ for $6 \mathrm{~h}$. The products on the substrates were washed with DI water and dried naturally at room temperature.

\section{Structural Characteristics}

Field emission scanning electron microscope (FESEM, by FEI Magellan 400) and X-ray diffraction (XRD, by Rigaku D/MAXUltima with $\mathrm{Cu} \mathrm{K} \alpha$ radiation) were used to characterize the microscopic morphology and crystal structure of the samples, respectively.

\section{Electrochemical Measurement}

The cyclic voltammetry (CV) and electrochemical impedance spectroscopy (EIS) of the samples have used electrochemical workstation (CHI760E) to test. AZO NSs on GPET substrates as a working electrode, $\mathrm{Ag} / \mathrm{AgCl}$ as a reference electrode, and platinum foil as counter electrode comprise the three-electrode test system. $1 \mathrm{~mol} / \mathrm{L} \mathrm{Na}_{2} \mathrm{SO}_{4}$ solution be used as electrolyte in this process of electrochemical measurement.

\section{RESULTS AND DISCUSSION}

The SEM and XRD images of $\mathrm{ZnO}$ with different $\mathrm{Al}$ doped concentration (doping concentrations of $0,0.05$, and $0.1 \mathrm{~mol} / \mathrm{L}$ ) prepared on GPET substrates are seen in Figure 1. As shown in Figure 1A, in the case of the undoped $\mathrm{Al}$ elements, $\mathrm{ZnO}$ has a vertically arranged NR structure with hexagon of its top and a uniformly dense cover on the surface of GPET substrate, suggesting that undoped $\mathrm{ZnO}$ has a good degree of orientation. With the addition of $\mathrm{Al}$ elements, the structure of $\mathrm{ZnO}$ is gradually changed from NR to NS, which clearly observed in Figures 1B,C. It is not difficult to see that AZO NSs, with its smooth surface, still grow perpendicularly to the GPET substrate and are connected together to form a network structure. Compared with the $\mathrm{ZnO} \mathrm{NRs}$, the conductivity of obtained electrodes of the AZO NSs can be improved due to the fact that the AZO NSs array can develope the branched network. And the pseudo-capacitance of $\mathrm{ZnO}$ nanostructure may improve its capacitance value and thus obtain an excellent 

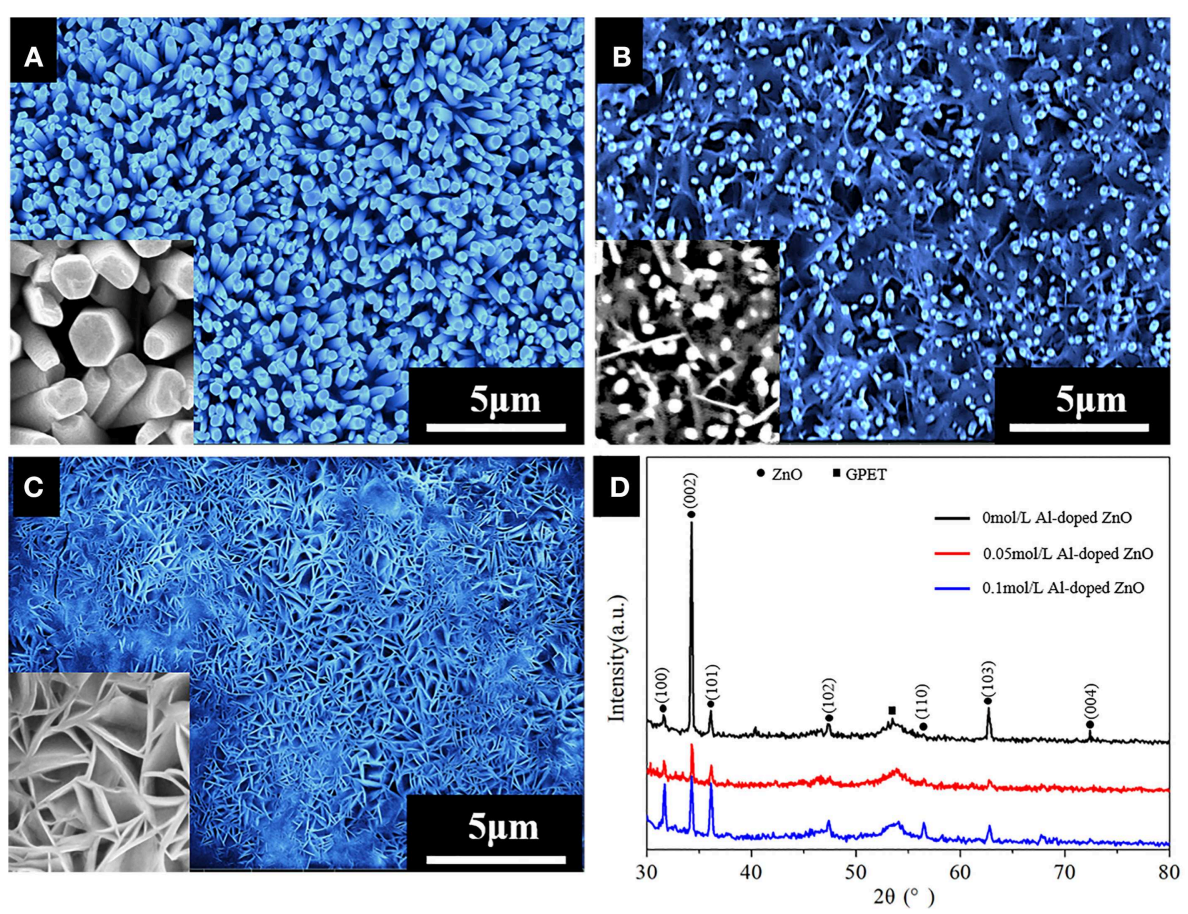

FIGURE 1 | (A-C) FE-SEM image of Al-doped ZnO nanostructure grown on GPET substrate at different Al doped concentration: (A) 0 mol/L; (B) 0.05 mol/L; (C) $0.1 \mathrm{~mol} / \mathrm{L}$; (D) XRD spectra of all samples. The inset in (A-C) correspond high-magnification images.

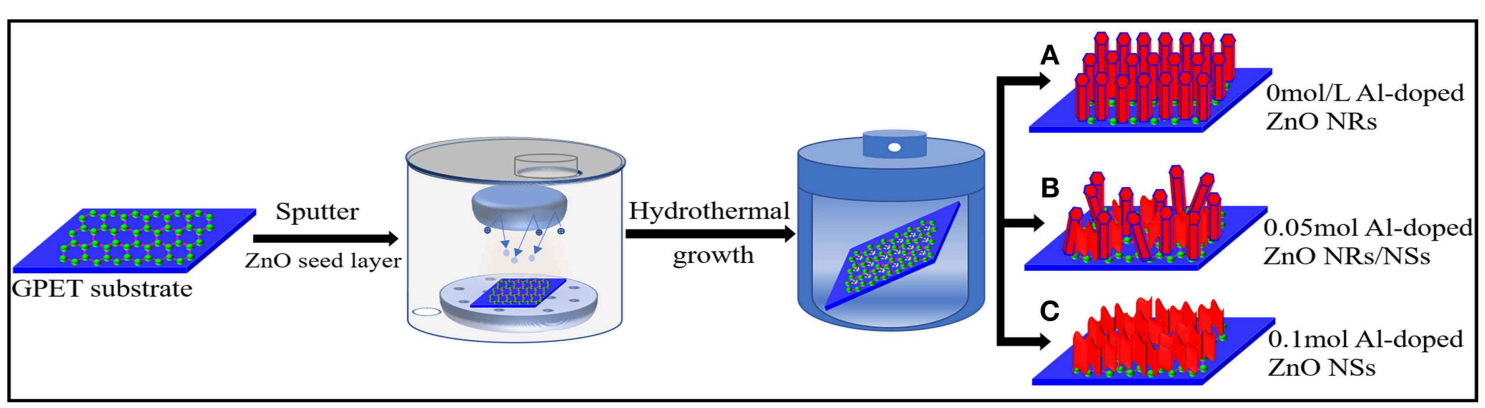

FIGURE 2 | Schematic diagram of hydrothermal growth mechanism of $\mathrm{ZnO}$ nanostructures.

electrochemical property (Zhang et al., 2015). As can be seen from the XRD image (Figure 1D), except for the characteristic peaks belonging to graphene and GPET substrate appearing at $26^{\circ}$ and $54^{\circ}$, the other peaks are the diffraction peaks of $\mathrm{ZnO}$, which are basically in agreement with the standard PDF card (JCPDS 89-1397) of ZnO. Moreover, the (002) diffraction peak strength is higher than (100) and (101), which indicates that AZO grow preferentially perpendicular to the substrate along the $\mathrm{c}$-axis. The doping of $\mathrm{Al}$ generates stress during crystallization, and the crystal structure of $\mathrm{ZnO}$ changes accordingly. Further, the intensity of the diffraction peaks of (002) may become weak due to the incorporation of $\mathrm{Al}$ elements.
Schematic diagram of hydrothermal growth mechanism of $\mathrm{ZnO}$ NSs in Figure 2 revealed that incorporation of $\mathrm{Al}$ inhibits the growth of $\mathrm{ZnO}$ NRs, thereby forming AZO NSs. The $\mathrm{ZnO}$ crystal has a (0001) plane and a (0001) plane, that is, a $\mathrm{Zn}$ positive polar surface and an $\mathrm{O}$ negative polar surface and six non-polar surfaces. $\mathrm{Al}_{2} \mathrm{O}_{3}$ dissolved in the solution to produce complexing ions, and the positive polar surface (0001) of the $\mathrm{ZnO}$ lattice is more likely to adsorb the $\mathrm{Al}(\mathrm{OH})_{4}^{-}$complexing ions with negative charges, which can hinder the growth of $\mathrm{ZnO}$ along the [0001] direction. The growth of NRs was inhibited along c-axis, which promoted the lateral growth of $\mathrm{ZnO}$, and then formed $\mathrm{ZnO}$ NSs (Figure 2C; Koh et al., 2004). The main chemical reactions occurring in the solution during the formation of the $\mathrm{ZnO}$ NSs 
were involved in the following Equations (1) and (4):

$$
\begin{array}{r}
\mathrm{C}_{6} \mathrm{H}_{12} \mathrm{~N}_{4}+10 \mathrm{H}_{2} \mathrm{O} \rightleftharpoons 6 \mathrm{HCHO}+4 \mathrm{NH}_{3} \cdot \mathrm{H}_{2} \mathrm{O} \\
\mathrm{Zn}^{2+}+\mathrm{NH}_{3} \cdot \mathrm{H}_{2} \mathrm{O} \rightleftharpoons \mathrm{Zn}\left(\mathrm{NH}_{3}\right)_{4}^{2+} \\
\mathrm{Zn}\left(\mathrm{NH}_{3}\right)_{4}^{2+}+\mathrm{OH}^{-} \rightleftharpoons \mathrm{ZnO}+\mathrm{NH}_{3} \mathrm{H}_{2} \mathrm{O} \\
\mathrm{Al}+4 \mathrm{OH}^{-} \rightleftharpoons \mathrm{Al}(\mathrm{OH})_{4}^{-}
\end{array}
$$

In order to study the effects of different concentrations of $\mathrm{Al}$ doping on the electrochemical characteristics of $\mathrm{ZnO}$ nanostructures, the CV curves of three different samples were analyzed under a potential range of -0.8 to $0.9 \mathrm{~V}$ at scanning rates of $100 \mathrm{mV} / \mathrm{s}$.

The CV curves, which has been clearly observed by Figure 3A, revealed that redox peaks of $0.1 \mathrm{~mol} / \mathrm{L}$ AZO NSs can be significant observed, which indicated that the synthesized active substances are beneficial for rapid redox reactions $(\mathrm{Pu}$ et al., 2014). Comparing the integrated area of the samples on the current-potential axis (Figure 3A), it is well-known that the integrated area of the $0.1 \mathrm{~mol} / \mathrm{L} \mathrm{AZO} \mathrm{NSs} \mathrm{is} \mathrm{larger,}$ indicating that the $0.1 \mathrm{~mol} / \mathrm{L}$ AZO NSs has a stronger charge storage capacity. Further study on the of different scanning rates of $5,10,20,30,50$, and $100 \mathrm{mV} / \mathrm{s}$ on the electrochemical characteristics of $0.1 \mathrm{~mol} / \mathrm{L} \quad \mathrm{AZO}$ NSs nanostructures (Figure 3B), and the results showed that the electrical current density increases with the increases of scan rates, which confirmed that $0.1 \mathrm{~mol} / \mathrm{L}$ AZO NSs nanomaterials have excellent scanning ability.

The Nyquist plots of AZO/GPET electrodes are shown in Figure 4. The impedance curves of all obtained samples consisted of high frequency zones (shown as semicircle), which reflects the charge transfer resistance $\left(R_{\mathrm{ct}}\right)$ of the electrode, and low frequency zones (shown as slash),
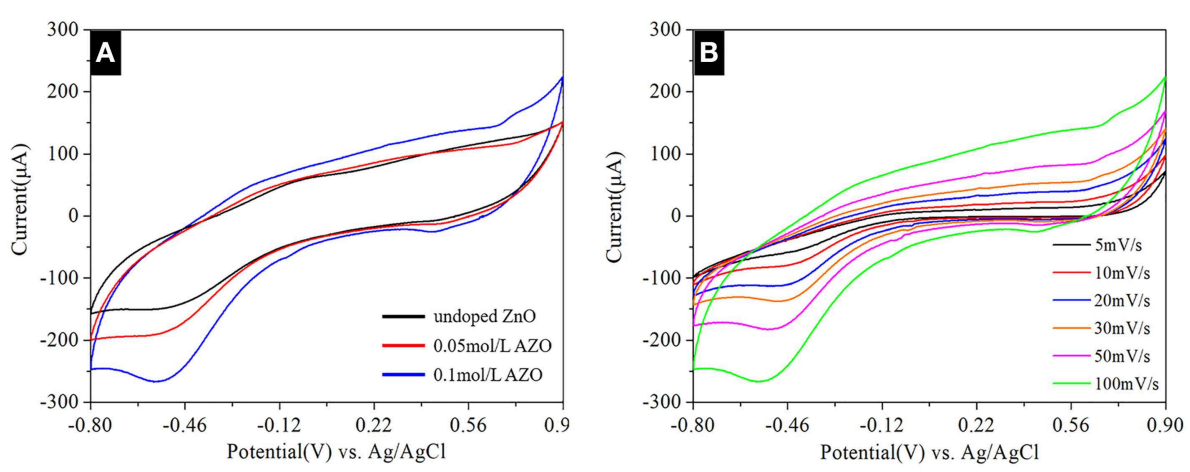

FIGURE 3 | (A) CV curves of all samples at a scan rate of $50 \mathrm{mV} / \mathrm{s}$. (B) CV curves of $0.1 \mathrm{~mol} / \mathrm{L}$ AZO nanostructures grown on GPET substrates with different scan rates in the range of $5-100 \mathrm{mV} / \mathrm{s}$.

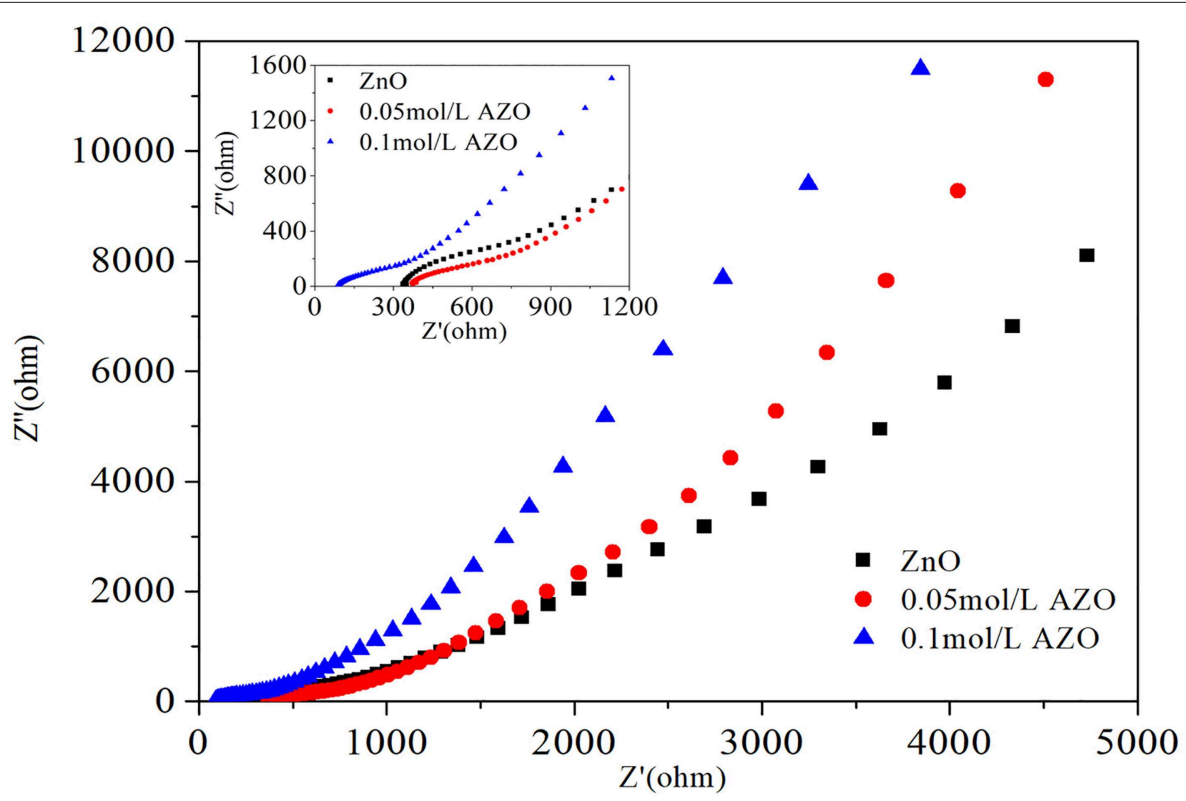

FIGURE 4 | Nyquist plots of $0 \mathrm{~mol} / \mathrm{L} \mathrm{ZnO}, 0.05 \mathrm{~mol} / \mathrm{L} \mathrm{AZO}$, and $0.1 \mathrm{~mol} / \mathrm{L}$ AZO. Inset is the enlarged high frequency zones. 
which mirrors the diffusion resistance of the ions of the electrode. The semicircular diameter of the high-frequency zone is basically the same, indicating that the addition of $\mathrm{Al}$ does not enhance the charge transfer ability of $\mathrm{ZnO} / \mathrm{GPET}$ electrode. In the low frequency zones the diffusion rate of electrode is proportional to the slope of impedance curve. The diffusion rate of AZO/GPET electrode is significantly greater than that of $\mathrm{ZnO} / \mathrm{GPET}$ electrode, which indicated that AZO/GPET electrode has better electrochemical properties.

\section{CONCLUSIONS}

In summary, AZO NSs, which are evenly grown perpendicular to the GPET substrate, were successfully prepared using hydrothermal method assisted by ion sputtering. The structure, microscopic morphology and growth mechanism of the samples were analyzed, and it was concluded that the incorporation of $\mathrm{Al}^{3+}$ inhibited the growth of $\mathrm{ZnO}$ NRs, but promoted the formation of $\mathrm{ZnO} \mathrm{NSs}$, and weakened the characteristic diffraction peak intensity of $\mathrm{ZnO}$ growing perpendicular to the substrate along the c-axis. The electrochemical performance test of the samples concluded that the AZO NSs have

\section{REFERENCES}

Abbey, C., and Joos, G. (2007). Supercapacitor energy storage for wind energy applications. IEEE Trans. Ind. Appl. 43, 769-776. doi: 10.1109/TIA.2007.895768

Bhirud, A., Sathaye, S., Waichal, R., Park, C. J, and Kale, B. (2015). In situ preparation of $\mathrm{N}-\mathrm{ZnO} /$ graphene nanocomposites: excellent candidate as a photocatalyst for enhanced solar hydrogen generation and high performance supercapacitor electrode. J. Mater. Chem. A 3, 17050-17063. doi: 10.1039/C5TA03955J

Biplab, K. D., Ankita, H., and Jisoo, K. (2017). Recent development and challenges of multifunctional structural supercapacitors for automotive industries. Int. J. Energ. Res. 41, 1397-1411. doi: 10.1002/er.3707

$\mathrm{Bu}$, I. Y. Y., and Huang, R. (2015). One-pot synthesis of $\mathrm{ZnO} /$ reduced graphene oxide nanocomposite for supercapacitor applications. Mat. Sci. Semicon. Proc. 31, 131-138. doi: 10.1016/j.mssp.2014.11.037

Cao, J., and Emadi, A. (2011). A new battery/ultracapacitor hybrid energy storage system for electric, hybrid, and plug-in hybrid electric vehicles. IEEE Trans. Power Electr. 27, 122-132. doi: 10.1109/TPEL.2011.2151206

Faraji, S., and Ani, F. N. (2014). Microwave-assisted synthesis of metal oxide/hydroxide composite electrodes for high power supercapacitors - a review. J. Power Sources 263, 338-360. doi: 10.1016/j.jpowsour.2014.03.144

Futaba, D. N., Hata, K., Yamada, T., Hiraoka, T., Hayamizu, Y., Kakudate, Y., et al. (2006). Shape-engineerable and highly densely packed single-walled carbon nanotubes and their application as super-capacitor electrodes. Nat. Mater. 5, 987-994. doi: 10.1038/nmat1782

Han, W. J., Ren, L., Gong, L. J., Qi, X., Liu, Y. D., Yang, L. W., et al. (2014). Self-assembled three- dimensional graphene-based aerogel with embedded multifarious functional nanoparticles and its excellent photoelectrochemical activities. ACS Sustain. Chem. Eng. 2, 741-748. doi: 10.1021/sc400417u

Isabel, P. P., David, S. T., Ramiro, R. R., Emilia, M., and Diego, C. A. (2016). Design of activated carbon/activated carbon asymmetric capacitors. Front. Mater. 3:16. doi: $10.3389 /$ fmats.2016.00016

Jacob, L., Prasanna, K., Vengatesan, M. R., Santhoshkumar, P., Lee, C. W., and Mittal, V. (2018). Binary $\mathrm{Cu} / \mathrm{ZnO}$ decorated graphene nanocomposites as an efficient anode for lithium ion batteries. J. Ind. Eng. Chem. 59, 108-114.doi: 10.1016/j.jiec.2017.10.012 better electrochemical performance than the undoped $\mathrm{ZnO}$ NRs, which have broad application prospects in the field of capacitors.

\section{DATA AVAILABILITY}

All datasets generated for this study are included in the manuscript/supplementary files.

\section{AUTHOR CONTRIBUTIONS}

QY contributed to the research and result analysis and discussion. SR, PR, YL, and LJ assisted in the synthesis and analysis of the materials. All authors contributed to the general discussion.

\section{FUNDING}

This work was financially supported by the National Natural Science Foundation of China (Grant no. 51502166), Scientific Research Program Funded by Shaanxi Provincial Department (Grant no. 17JK0130), and the Industrial Field of Key Research and Development Plan of Shaanxi Province (Grant no. 2018GY-040).

Klingshirn, C. (2010). The luminescence of $\mathrm{ZnO}$ under high one- and twoquantum excitation. Scripta Mater. 71, 547-556. doi: 10.1002/pssb.2220710216

Koh, Y. W., Ming, L., Tan, C. K., Yong, L. F., and Loh, K. P. (2004). Self-assembly and selected area growth of zinc oxide nanorods on any surface promoted by an aluminum precoat. J. Phys. Chem. B 108, 11419-11425. doi: 10.1021/jp049134f

Liu, W. J., Kao, T. W., Dai, Y. M., and Jehng, J. (2014). M. Nibased nanocomposites supported on graphene nano sheet (GNS) for supercapacitor applications. J. Solid State Electrochem. 18, 18189-18196. doi: $10.1007 /$ s10008-013-2263-4

Liu, X., Sheng, G., Zhong, M., and Zhou, X. (2018). Hybrid nanowires and nanoparticles of $\mathrm{WO}_{3}$ in a carbon aerogel for supercapacitor applications. Nanoscale 10, 4209-4217. doi: 10.1039/C7NR07191D

Narayanan, R., Kumar, P. N., Deepa, M., and Srivastava, A. K. (2015). Combining energy conversion and storage: a solar powered supercapacitor. Electrochim. Acta 178, 113-126. doi: 10.1016/j.electacta.2015.07.121

Pu, J., Wang, Z., Wu, K., Yu, N., and Sheng, E. (2014). Cog $S_{8}$ nanotubes arrays supported on nickel foam for high-performance supercapacitors. Phys. Chem. Chem. Phys. 16, 16785-16791. doi: 10.1039/C3CP54192D

Ren, J., Li, L., Chen, C., Chen, X., Cai, Z., Qiu, L., et al. (2013). Twisting carbon nanotube fibers for both wire-shaped micro-supercapacitor and micro-battery. Adv. Mater. 25, 1155-1159. doi: 10.1002/adma.201203445

Ren, S., Rong, P., and Yu, Q. (2018). Preparations, properties and applications of graphene in functional devices: a concise review. Ceram. Int. 44, 11940-11955. doi: 10.1016/j.ceramint.2018.04.089

Salinas-Torres, D., Ruiz-Rosas, R., Morallón, E., and Cazorla-Amorós, D. (2019). Strategies to enhance the performance of electrochemical capacitors based on carbon materials. Front. Mater. 6:115. doi: 10.3389/fmats.2019.00115

Wang, G., Wang, H., Lu, X., Ling, Y., Yu, M., Zhai, T., et al. (2014). Solidstate supercapacitor based on activated carbon cloths exhibits excellent rate capability. Adv. Mater. 26, 2676-2682. doi: 10.1002/adma.201304756

Wang, J., Zan, G., Li, Z. S., Wang, B., Yan, Y. X., Liu, Q., et al. (2011) Green synthesis of graphene nanosheets/ZnO composites and electrochemical properties. J. Solid State Chem. 184, 1421-1427. doi: 10.1016/j.jssc.2011.03.006

Wu, C., Chen, L., Lou, X., Ding, M., and Jia, C. (2018). Fabrication of cobalt-nickelzinc ternary oxide nanosheet and applications for supercapacitor electrode. Front. Chem. 6:597. doi: 10.3389/fchem.2018.00597 
Xu, X., Li, S., Zhang, H., Shen, Y., Zakeeruddin, S. M., Graetzel, M., et al. (2015). A power pack based on organometallic perovskite solar cell and supercapacitor. ACS Nano 9, 1782-1787. doi: 10.1021/nn50 $6651 \mathrm{~m}$

Yang, H., Ye, S., Zhou, J., and Liang, T. (2019). Biomass-derived porous carbon materials for supercapacitor. Front Chem. 7:274. doi: 10.3389/fchem.2019.00274

Zhang, Y., Zou, Q., Hsu, H. S., Raina, S., Xu, Y., and Kang, J. B. (2016). Morphology effect of vertical graphene on the high performance of supercapacitor electrode. ACS Appl. Mater. Inter. 8, 7363-7369. doi: 10.1021/acsami.5b1 2652

Zhang, Z., Ren, L., Han, W. J., Meng, L., Wei, X., and Qi, X. (2015), One-pot electrodeposition synthesis of $\mathrm{ZnO} /$ graphene composite and its use as binder-free electrode for supercapacitor. Ceram. Int. 41, 4374-4380. doi: 10.1016/j.ceramint.2014.11.127
Zhao, X., Sánchez, B. M., Dobson, P. J., and Grant, P. S. (2011). The role of nanomaterials in redox-based supercapacitors for next generation energy storage devices. Nanoscale 3, 839-855. doi: 10.1039/c0nr00594k

Conflict of Interest Statement: The authors declare that the research was conducted in the absence of any commercial or financial relationships that could be construed as a potential conflict of interest.

Copyright (๑) $2019 \mathrm{Yu}$, Rong, Ren, Jiang and Li. This is an open-access article distributed under the terms of the Creative Commons Attribution License (CC BY). The use, distribution or reproduction in other forums is permitted, provided the original author(s) and the copyright owner(s) are credited and that the original publication in this journal is cited, in accordance with accepted academic practice. No use, distribution or reproduction is permitted which does not comply with these terms. 